\title{
Use of Mobile Phones in the Classroom by College Students and Their Perceptions in Relation to Gender: A Case Study in China
}

\author{
Yelinjing Liu
}

\begin{abstract}
This study investigates the uses of mobile phone in the classroom and compares the attitudes of students in different genders towards the use of mobile phones in a Chinese university, to explore the influence of gender. The mixed research strategy was adopted to collect both quantitative and qualitative data. One hundred fifty-three undergraduates from a university in southwest China participated in the survey through questionnaires, and nine of them were interviewed in groups. The results indicated that there was no difference between men and women in their uses of mobile phones in the classroom and attitudes. However, girls were more likely than boys to use the affordances of content generation and education of mobile phones. The results showed that mobile phones were minimally used in education. Implications are presented for guiding students' use of mobile phones to assist the classroom learning. Suggestions for future research are provided.
\end{abstract}

Index Terms-Gender, mobile phones, attitudes, classroom use.

\section{INTRODUCTION}

With the development of science and technology as well as the popularity of the Internet, mobile teaching has become increasingly popular. In most parts of the world, this approach has been widely used [1]. Mobile learning is the way to use powerful retrieval, content generation, interaction , and other functions of mobile devices to carry out cloud learning and offline learning. In Chinese universities, this kind of new mobile teaching is developing gradually. The use of mobile phones by students in the class may involve a variety of advantages, which have been studied by researchers such as promoting interactive learning among students [2] and providing a lot of resources and learning support [3]. However, few studies have been conducted in the context of higher education in China. Particularly, little is known about how college students are using mobile phones to support learning in the classroom and how their uses may be affected by factors such as gender. For such research objectives, this study aims to understand college students' applications of and attitudes towards mobile phones inside the classroom and explore their relationships with gender. Specifically, four research questions have been guiding the study:

1) What do the students use mobile phones in the classroom?

2) What is the relationship between their uses of mobile

Manuscript received October 12, 2019; revised March 4, 2020.

The author is with Sichuan University, China (e-mail: 1017090807@qq.com). phones and gender?

3) What are the students' perceptions of using mobile phones in the classroom?

4) What is the relationship between their attitudes and gender?

The results of an investigation as such will provide specific implications for the design of mobile learning in the context of higher education. Additionally, by comparing the features of male and female students, appropriate strategies may be adopted for different learning activities based on the characteristics of different genders.

\section{LITERATURE REVIEW}

Many studies have shown that the use of mobile phones involves a range of advantages for classroom teaching and learning. As Bull and Thompson [4] put, digital image framework allows teaching products to be shared with other students without being limited to printed literature. Electronic cooperation tools enable more activities and products to be shared with other students, reduce costs ,and share content utilizing transmission. In the same way, mobile phones can also achieve sharing across time and space. Quinn [3] defines mobile learning as "the intersection of mobile computing and e-learning," which indicates lots of resources whenever you want, robust search capabilities, productive interaction, and powerful support of learning. It can shorten the distance between teachers and students [1] and may also challenge the traditional teaching model, making learning more learner-centered [5]. Also, in a study of introducing mobile phones and short messages service within the classroom, Markett [2] discovered that mobile phones brought some benefits of interactivity, like improving the learning environment to increased students' interest and motivation. Even the gap between formal and informal learning can be bridged to encourage students' learning ability in naturalistic settings and develop their context-specific competences [6]. Robson [7] assume that mobile technology has advanced which could meet several requirements such as word processing, online information search ,and retrieval (including eBooks), testing in all subjects, computation, data acquisition, visually displaying and processing information, and genuine access to diverse languages and cultures. Additionally, Elizabeth and Frank [8] did interesting research in Australia to figure out what young people would contribute to their learning by using a mobile camera. It was identified that using mobile technologies crossed boundaries between school and social contexts, 
allowing students to take school knowledge to a broader social arena.

In contrast, there also exist disadvantages of using mobile phones for classroom teaching and learning. Although a lot of schools banned the use of mobile phones, students still ignored these restrictions taking their phones to school. Lenhart and Purcell [9] made further investigation , and they found that some students kept their phones on and used it during class. With new opportunities came new problems. Students who took their mobile phone to school always texted messages in the class, cheated in the tests, and performed mobile harassment. What is worse, cell phones afforded a new venue for bullying. Because of the lean channel of texting, bullies and harassers could stay connected to their targets easily. Moreover, according to Shelton et al. [10], mobile phone ringtones in the class could seriously interfere with students' memory of the information presented by mobile phone ringtones. Meanwhile, mobile phone ringtones are destructive in the classroom environment and will disturb students' cognitive performance. The impact of using mobile phones in the class is hard to avoid entirely. What's more, most of the students have acquired the way to use mobile devices so that they would be little trained [11] However, large-scale studies on students' application of mobile technologies reveal that different age groups and different socio-economic backgrounds have a significant impact on students' mastery of Internet knowledge [12]. Prensky [13] proposes a concept to divide people into digital natives and digital immigrants as there are so many differences within and between generations of digital natives [14]. When introducing mobile phones into the classroom, if we generalize about students in the class and focus on those who are good at mobile technology, then students who are not good at mobile technology are likely to be ignored. They may not benefit from the mobile learning environment, which is detrimental to their learning. Moreover, teachers' attitudes in mobile learning are also necessary. Many teachers are increasingly supportive of students using mobile phones in the classroom, but teachers also need regular training and specialized technical guidance. Besides, some teachers need to overcome psychological maladjustment and develop self-confidence to adapt to mobile technology [12].

There are also studies discussing students' attitudes towards using mobile phones in the class. In the research of using short message service to enhance classroom interaction, Markett [2] found that the opportunity to use a new technology viewing comments, responding in multiple mediums and texting in the class led students to some satisfaction. Most of them expressed their support of using the mobile phone in the class in the future and suggested additional appropriate activities. Besides, students seemed glad to try some mobile devices, and positive results were obtained. Take Chang and Hsu's [15] experiment as an example, more than 70 percent of the students agreed that a computer-aided language system based on a PDA worked well, and the experimental results also showed that the group learning with the system was better. Kim [16] also surveyed to study students' opinions on mobile learning in TESOL courses at an American university. According to the results, students had a positive response to the use of mobile technology for language learning. It also showed the potential of mobile devices to facilitate learning new learning experiences and provide more learning opportunities. During the study of exploring the way to use mobile technologies in informal learning, Cook et al. [17] gain mixed results which showed that students not only saw the potential of mobile phone for social networking and essential matters but also captured the features of mobile phones that could be used in recording interviews, taking photos, communicating text, and phone calls. Agreeing with Sefton-Green [18], students who took part in informal learning using a mobile phone outside the classroom activities related to class content. Hsu's [19] found that participants from different cultural backgrounds scored differently and generally showed a positive attitude to mobile learning. When the class is composed of learners from different cultural backgrounds, special attention should be paid to adjusting the individual's cultural response to mobile-assisted learning.

As indicated in the studies reviewed, the application of mobile devices in the classroom is influenced by factors such as policy background, social environment, cultural cognition differences, usage methods, and attitudes of teachers and students. The use of mobile devices in western countries is more common than that in Chinese educational contexts. The existing research related to mobile learning conducted in China mainly focused on English learning, which was more about the use of specific software and systems rather than mobile phones. Moreover, few studies have been conducted regarding the attitudes of learners using mobile devices in the class. Research specifically exploring gender impact is even less. These are the research gaps that the present study aims to fill.

\section{Methodology}

\section{A. Research Context and Participants}

This study was conducted in a university located in the southeast of China. It was a key and comprehensive university consisting of 32 colleges and including 6,900 students from all over the world. Due to its comprehensiveness and diversity, this university may more objectively reflect students' uses of and views on mobile phones in the class.

The questionnaires and consent forms were circulated through official groups which were set up by the registration office of the university to organize university-level activities. The groups contained members from different schools. There were three official QQ groups with 2,000 people each and two official WeChat groups with 500 people each. A total of 449 questionnaires were sent, and 153 valid responses were received. The participants were all undergraduates of the university in different grades. Among them, 45 were male ,and 108 were female.

\section{B. Data Collection Methods}

This research adopted the mixed research design combining quantitative and qualitative research methods, which is an effective way to strengthen reliability and validity [20]. The quantitative data was collected through 
questionnaires, which was adapted from the work of O'Bannon and Thomas [21]. Since all the students participating in this study were Chinese students, the questionnaires were translated into Chinese so that participants can better understand the meaning of the options. The questionnaires contained 37 items focusing on college student' uses and perceptions of mobile phones in the classroom to examine their relationships with gender. Different types of questions were included, including Yes/No questions, checklists, and Likert-scaled questions using five-point scales (form disagree strongly to agree strongly).

Although questionnaires can break the boundaries of time and space to collect as many answers as possible from participants, there are still have more needs to be conducted to gain a closer look at what they do. Therefore, more direct methods, such as interviews, help investigators understand more detailed information to explore the complex meaning behind the questionnaire [22]. Thus, the data collection included two phases. The first phase was an online survey , and then face-to-face interviews were conducted.

Focus groups were utilized for the collection of qualitative data. The interviewees were selected from the participants who participated in the questionnaire survey. A total of nine interviewees were selected and divided into two groups according to gender, including four boys in one group and five girls in the other group. Basic information has been shown in the following table (see Table 1). For ethical concerns, pseudonyms were used in this study when quoting the qualitative data.

TABLE I: INFORMATION ON INTERVIEWEES

\begin{tabular}{llll} 
& \multicolumn{2}{c}{ TABLE I: INFORMATION ON INTERVIEWEES } \\
\hline Name & Gender & Grade & Discipline \\
\hline Li & Male & 2017 & Liberal arts \\
Liu & Male & 2017 & Business \\
Wu & Male & 2015 & Science \\
Cheng & Male & 2014 & Engineering \\
Bin & Female & 2016 & Engineering \\
Han & Female & 2015 & Liberal arts \\
Hui & Female & 2015 & Liberal arts \\
Xu & Female & 2014 & Business \\
Tao & Female & 2016 & Science \\
\hline
\end{tabular}

In the selection of interviewees, specific aspects were focused on, such as educational backgrounds, majors ,and grades. The respondents came from different colleges and majors of the university, covering science, business, arts ,and engineering. They come from different grades (year of enrollment). Focus groups were conducted around the following questions: 1). What do you do with your mobile phone in the classroom? 2). Do teachers in your faculty allow the students to use mobile phones in the classroom? Why or why not? 3). Do you think mobile phones should be allowed in the classroom? Why or why not? 4). What do you think of using mobile phones to support teaching and learning in the classroom? The interviews were conducted in Chinese, and then transcribed into English. Each group was interviewed for about 60 minutes.

\section{Data Analysis}

To address the research questions, after receiving 153 valid questionnaires, the data were processed. First, mobile phone USES were divided into five categories according to the situations indicated in the questionnaires, including instant messaging, entertainment, content generation, education, and others (see Table II).

TABLE II: CATEGORIZATIONS OF MOBILE PHONE USES

\begin{tabular}{ll} 
Classification & Contents \\
\hline Instant messaging & send/receive a text message, email, WeChat, \\
QQ ,etc. & surfing the Internet, watching videos, listening to \\
music or radio, playing games, social networking, & and online shopping \\
record/posting videos, taking/posting pictures, & recording \\
Content generation & downloading and educational apps \\
Eding clock/timer, calendar, calculator, creating & and scanning QR codes
\end{tabular}

Situations of students using mobile phones in the class were analyzed based on the classifications above. Next, the uses of mobile phones by boys and girls were respectively explained, and the data was integrated into a chart to illustrate the differences. Besides, the descriptive analysis method was adopted to interpret the differences between boys and girls in their uses of mobile phones in the classrooms. When explicitly discussing students' cognitive and gender differences, we applied the Statistical Package for Social Science (SPSS) to analyze the quantitative data. Independent t-test was performed to determine whether there was a significant difference between boys' and girls' attitudes towards using mobile phones.

In the process of qualitative data analysis, content analysis was conducted to achieve triangulation and confirm the conclusion [23]. Content analysis is a method to classify written or oral materials into identification categories with similar meanings [24]. It interprets textual data content through the classification process of identifying themes or patterns [25]. As Schreier [26] argued, it is a systematic method to describe the significance of qualitative materials.

\section{REsults}

\section{A. Students' Uses of Mobile Phones in the Classroom}

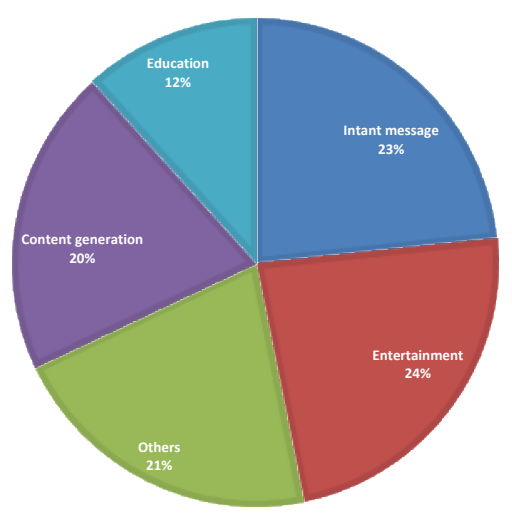

Fig. 1. Students' uses of mobile phone in the classroom.

From Fig. 1, it could be seen that students mainly used mobile phones for entertainment and instant messaging, with the former accounting for $24 \%$ and the latter accounting for $23 \%$. In contrast, students were less likely to use education-related mobile phone functions in the classroom, which accounted for the least at $12 \%$. As Xu said, "It is very widespread to use the photo and audio recording function in 
the class, because it is convenient to review and organize notes after class." In contrast, Zhou explained that "liberal arts students don't study math, so we hardly need calculators or other tools in the class. Sometimes I have no interest in teachers' development, so that I will browse some websites and e-books by myself in the class".

\section{B. Relationship between Uses of Mobile Phones and Gender}

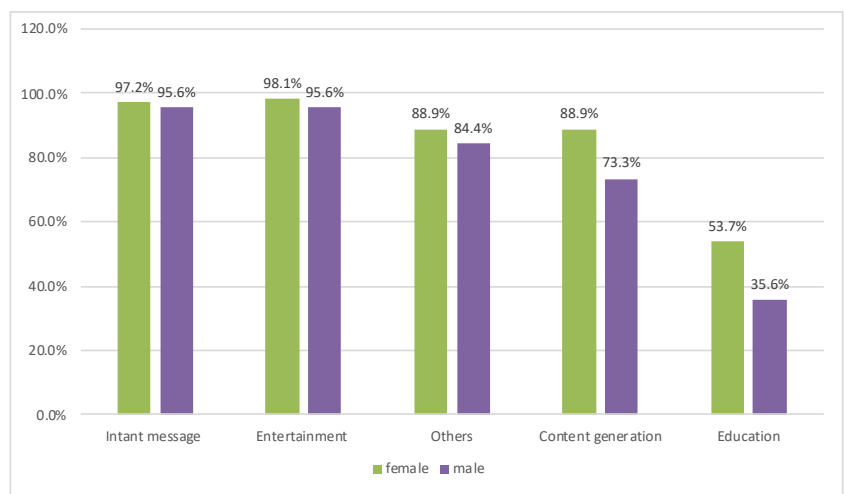

Fig. 2. Relationship between uses of mobile phones and gender.

As can be seen from Fig. 2, there was no significant difference between boys and girls in using mobile phones. More than $95 \%$ of boys and girls used instant messaging and entertainment functions. Relatively speaking, girls used content generation and educational services more than boys. In terms of content generation, the utilization rate of female students reached $88.9 \%$, while that of male students was more than 10 percent lower. In terms of educational software, the probability of using educational software for girls was higher than that for boys, which was $8.7 \%$.

Han accounted that "girls tend to take notes carefully, so the use of mobile phones to take photos and video is helpful to help them improve their notes after class." Liu, on the other hand, felt that recording key words was enough for learning. His roommates thought that it was not necessary to use mobile phones to record extra information in the class. At the same time, girls felt that educational platform, such as apps for reading was helpful in understanding the lecture content, which were not appreciated by boys.

\section{Students' Perceptions of Using Mobile Phones in the Classroom}

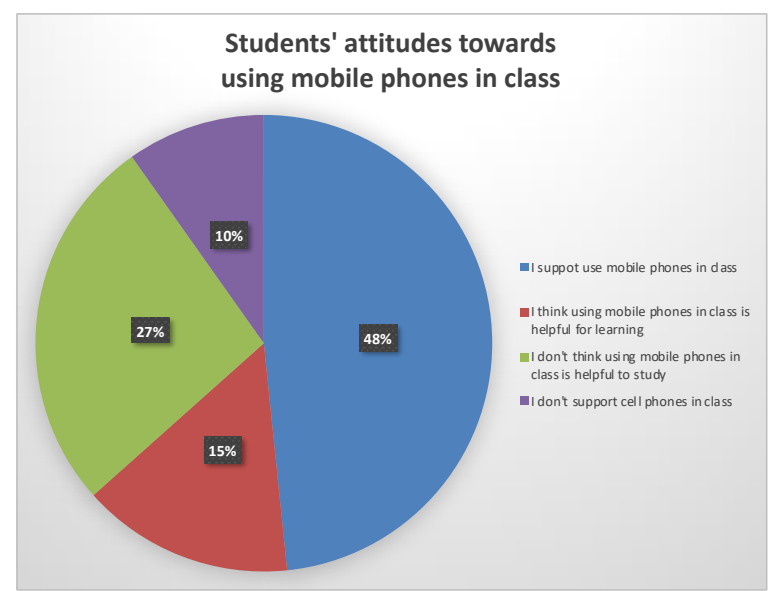

Fig. 3. Students' perceptions of using mobile phones in the classroom.

It could be seen from Fig. 3 that most students supported using mobile phones in the class, up to $48 \%$. On the contrary, one in ten students did not support the use of mobile phones in the class. As for whether using mobile phones in the class was conducive to learning, more people think that using mobile phones in the class did not help to learn twice as many as those who supported it. As Bin explained, "the regular use of mobile phones in the class can help to learn. For example, mobile phones can be used as a tool to assist learning and facilitate data access and notes are sorting. But if left unchecked, most students' autonomy is not enough to resist the lure of mobile entertainment, which can hinder learning."

\section{Relationship between Attitudes and Gender}

The differences in attitudes of male and female students towards using mobile phones in the class were analyzed by t-test procedures, and the results have been presented in the table above (see Table III). As shown in the table, there was no significant difference between men and women in their attitudes towards using mobile phones in the class. The overall views of both genders were very similar. In terms of answering the telephone, women $(M=3.59)$ were slightly higher than male $(M=3.09)$. As Bin said, "when a phone rings in the class, it should be immediately hung up. If it's important, you can reply by text messaging." Furthermore, there was also little difference in attitudes between women and men when it came to playing with their phones $(t=0.139$, $p p>.05)$, surfing the Internet $(t=-0,393, p p>.05)$, cheating $(t=-0.770, p>.05)$, and dealing with spam messages $(t=-0.894$, $p p>.05)$.

TABLE III: RELATIONSHIP BETWEEN PERCEPTIONS AND GENDER

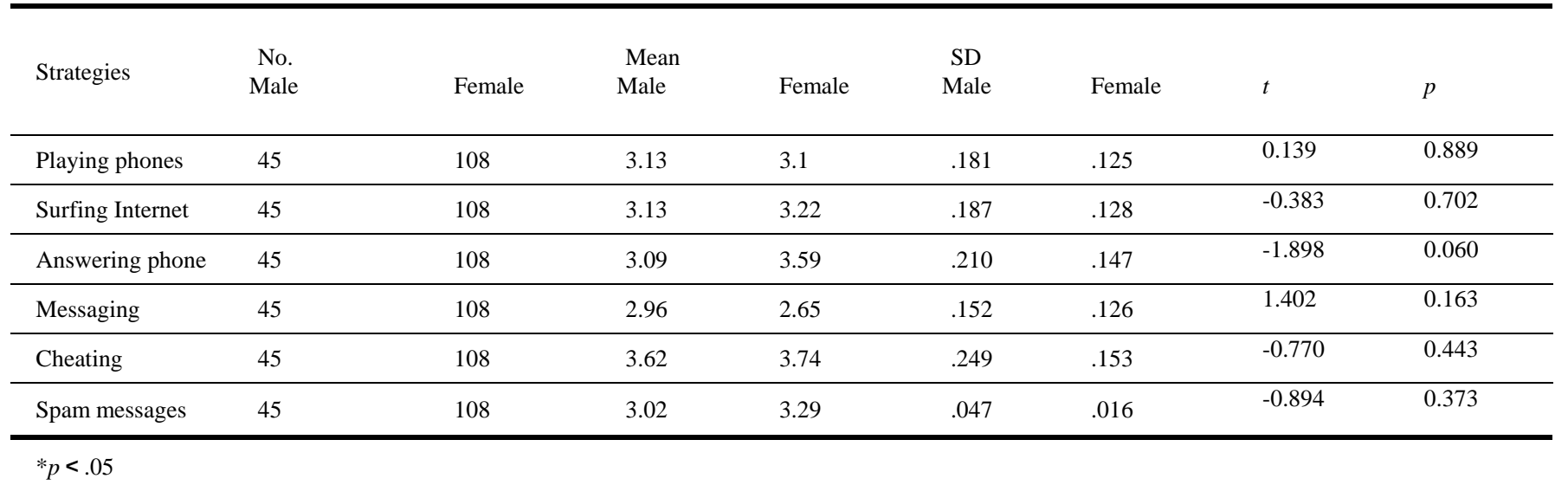




\section{DISCUSSION}

\section{A. Students' Uses of Mobile Phone inside the Classroom}

As indicated in the results, although college students all used mobile phones, the entertainment function of mobile phones was the main function that they used in the class. Students tended to use educational affordances of mobile phone at least. While it has been shown that using mobile phones has many benefits for classroom teaching, such as reducing the distance between teachers and students, improving the learning environment, and promoting students' interests and motivation [2], [4], it was not identified in this study.

As implied by the participants, the university still adopts the traditional teaching model, that is, teachers give lectures, and students listen to them. Teachers mainly use the blackboard to write and PPTs to show teaching contents, so that students can use the content generation function (such as taking pictures and recording) to support learning. However, due to the influence of teachers' teaching style and contents, many students feel bored and tend to wander off. More students use mobile phones to surf the Internet and communicate socially. Thus, the use of entertainment functions in the class is high. There are specialized online courses that require students and teachers to use educational apps for learning. However, according to the research results, when using these apps, students only use the most basic functions of checking in and handing in homework, rather than using apps to assist learning.

In terms of this phenomenon, Prensky [13] proposes the concept of digital natives and digital immigrants, pointing out that there are students who are good at using mobile technology and students who are not good at using mobile technology. Ertmer and Leftwich [27] emphasize that teachers' attitude towards mobile learning is equally important, and some teachers need to participate in regular training and professional technical guidance personnel to adapt to mobile technology. To sum up, teaching mode is one of the important factors affecting students' use of mobile phones in the class. The use of mobile phones in the classroom is influenced by the course design, the improvement of which will help students to use mobile phones for classroom learning.

\section{B. Application of Mobile Phone inside the Classroom in Relation to Gender}

There was no significant difference between boys and girls in the use of mobile phone except in two aspects: instant content generation and educational functions. Instant content generation included the use of mobile photography, videoing, and recording. The same as Bull and Thompson [4], who mentioned that the digital image framework allows for the sharing of educational products with other students, and that electronic collaboration tools enable more activities and products to be shared with other students, reducing transmission costs and sharing content. Taking and uploading photos and videos via mobile phones allows instant recording content to be shared with others. When students miss the knowledge points, they can share their notes and blackboard writing with each other to supplement the learning content.

Although data collected through questionnaires indicated that there was no significant difference between boys and girls in the use of mobile phones in the class, differences in students' purposes were reflected by participants during the interviews. Female participants revealed that they liked to take detailed notes, such that they used such functions as taking pictures in the class to help organize information after class. Men, on the other hand, reported that they were more likely to record keywords, such that they used these relevant functions less in quality. This may be due to the reason that the new courses that need to be combined with mobile phones are the public elective courses, which are mainly about liberal arts. There are far more women in liberal arts courses than men, such that more classroom sharing, and educational application of mobile phones occur.

Like Lenhart and Purcell' [9] study, students' use of mobile phones in the classroom learning also involves some adverse effects. The interviewees admitted that many students were using mobile phones in the class, browsing websites irrelevant to the learning contents, sending and receiving messages, chatting in the class, playing games, and watching dramas, which exerted specific influences on the people around them. Some people even used mobile phones to cheat in the classroom tests.

Besides, the study discovers that the use of mobile phones in the class had certain relationships with students' study habits. Moreover, students' self-control on mobile phones affects their choices of using mobile phone functions in the class. The auxiliary services of educational services need to be based on the information screening system to avoid the distraction of students when using them. At the same time, the teacher could assign a review of course contents and share learning resources through mobile technologies so that mobile phones can be better used for students learning.

\section{Students' Perceptions of Classroom Use of the Mobile Phone in Relation to Gender}

The results of this study support finding that students themselves know the benefits of mobile phones (Thomas, 2011) [11]. Students expect that new teaching models facilitated with mobile technologies could be adopted. In terms of current teaching mode, some students do not support the use of mobile phones and think that using mobile phones in the class does not help to learn. Interestingly, some interviewees believed that mobile phones were too tempting for students with poor self-control and could not promote or even hinder learning. As a result, they used mobile phones for some entertainment activities, and send and receive information in the class.

It can be noted that students' self-control is a factor that must be considered when applying mobile phones in the class, which can be restrained by software selection. For example, only relevant functions or apps can be used in the classroom ,and rules could be set guiding the use of these selected apps. At the same time, when the class is composed of learners from different cultural backgrounds, we should consider the proficiency of diverse students in using mobile devices, carry out necessary training, and take care of some 
people who are not used to using mobile phones.

Regarding the main functions of using mobile phones in the class, men and women have similar attitudes towards playing mobile phones, surfing the Internet, sending messages, cheating in exams, and browsing information. However, men and women interviewed showed different ideas about answering the phone. Male respondents believed that when receiving a call-in during the class, they should signal with the teacher to leave the classroom and answer it. By contrast, women thought that they should hang up immediately, call back after class or text back later. The results of this study support the previous finding that ringtone could seriously affect students' memory of learning knowledge in the class while damaging the classroom environment and interfering with students' cognition [10].

\section{Implications}

Some implications can be drawn from the results of this research to guide students regarding how to use mobile phones to assist learning, which could also be used as a reference for the reform of educational mode in the context of higher education in China. First, the present study shows that students are optimistic about the significance of mobile phones in tutoring learning in the class. They agree that mobile devices can promote new learning experiences and help acquire learning abilities. Although students themselves use entertainment affordances of mobile phones in the class more frequently, they generally oppose the use of apps irrelevant to learning and indicate that lack self-control is one of the primary reasons for this.

In the process of using mobile phone apps in the classroom teaching, students' situation should be fully considered, and some restrictions should be set, such as not allowing other apps to push information when using teaching apps. The teacher should combine the powerful resources of mobile phones and the function of instant searching and sharing, to promote content generation by students and facilitate their learning with mobile devices.

Also, the present research shows that teachers' classroom teaching mode and thinking are also essential factors influencing students' use of mobile phones in the class. To promote mobile teaching in a formal learning context, it is necessary to strengthen teachers' proficiency in the use of mobile technologies. Moreover, they should also have a basic understanding of students' use of mobile phones. In addition to the necessary affordances provided by the mobile technologies, such as roll call and check-in, mobile devices should be utilized as a tool to upload teaching data and information for students to review after class or communicate with teachers online.

\section{CONCLUSION}

This study extends the understanding of students' uses of and views on mobile phones in the classroom to gender. However, the research methods used in this study have their inherent limitations. Although the questionnaire survey results were consistent with the findings of qualitative interviews, the reliability and validity of the instruments adopted were not tested. In addition, the number of populations in this study was also not big enough. Another limitation is that the results derived much from self-reported data. However, the findings of this study may be generalized to other Chinese universities of the same type ,although further research is needed to test the results. The results indicate that classroom teaching mode is one of the critical factors affecting students' use of mobile phones in the class. Thus, course design should be improved to guide students on how to use mobile phones to help to learn correctly. However, this needs to be further investigated by future studies.

\section{CONFLICT OF INTEREST}

The authors declare no conflict of interest.

\section{REFERENCES}

[1] D. Wang, B. Zou, and M. Xing, "Vocabulary learning and consolidation with mobile application," International Journal of Computer-Assisted Language Learning and Teaching, vol. 4, no. 1, pp. 101-112, 2014.

[2] C. Markett, I. A. Sánchez, S. Weber, and B. Tangney, "Using short message service to encourage interactivity in the classroom," Computers \& Education, vol. 46, no. 3, pp. 0-293, 2006.

[3] C. N. Quinn, "M-Learning devices," Performance to Go, 2008.

[4] G. A. Bull, "Establishing a framework for digital images in the school curriculum," Learning \& Leading with Technology, vol. 31, pp. 14-17, 2004.

[5] S. Bibby, "Do students wish to 'go mobile': An investigation into student use of PCs and cell phones," International Journal of Computer-Assisted Language Learning and Teaching, vol. 1, no. 2, pp. 43-54, 2011.

[6] C. K. Looi, P. Seow, B. Zhang, H. J. So, W. Chen, and L. H. Wong, "Leveraging mobile technology for sustainable seamless learning: A research agenda," British Journal of Educational Technology, vol. 41, no. 2, pp. 154-169, 2010.

[7] R. Robson, "Mobile learning and handheld devices in the classroom," Eduworks Resources Library, 2003.

[8] E. Hartnell-Young and F. Vetere, "A means of personalizing learning: Incorporating old and new literacies in the curriculum with mobile phones," Curriculum Journal, vol. 19, no. 4, pp. 283-292, 2008.

[9] A. Lenhart, R. Ling, S. Campbell, and K. Purcell, "Teens and mobile phones: Text messaging explodes as teens embrace it as the centerpiece of their communication strategies with friends," Pew Internet \& American Life Project, 2010.

[10] J. T. Shelton, E. M. Elliott, S. D. Eaves, and A. L. Exner, "The distracting effects of a ringing cell phone: An investigation of the laboratory and the classroom setting," Journal of Environmental Psychology, vol. 29, no. 4, pp. 513-521, 2009.

[11] K. Thomas, C. Orthober, and N. Schultz, "Using text-messaging in the secondary classroom," in Proc. Society for Information Technology \& Teacher Education International Conference, pp. 2159-2164, Association for the Advancement of Computing in Education (AACE), 2009.

[12] P. A. Ertmer et al., "Professional development coaches: Perceptions of critical characteristics," Journal of School Leadership, vol. 15, no. 1, pp. 52-75, 2005.

[13] M. Prensky, "Digital natives, digital immigrants part 1," On the Horizon, vol. 9, no. 5, pp. 1-6, 2001.

[14] S. Bennett, K. Maton, and L. Kervin, "The 'digital natives' debate: A critical review of the evidence," British Journal of Educational Technology, vol. 39, no. 5, pp. 775-786, 2008.

[15] C. Chang and C. Hsu, "A mobile-assisted synchronously collaborative translation-annotation system for English as a foreign language (EFL) reading comprehension," Computer Assisted Language Learning, vol. 24, no. 2, pp. 155-180, 2011.

[16] D. Kim et al., "Students' perceptions and experiences of mobile learning," Language Learning \& Technology, vol. 17, no. 3, pp. 52-73, 2013.

[17] J. Cook, N. Pachler, and C. Bradley, "Bridging the gap? Mobile phones at the interface between formal and informal learning," Journal of the Research Center for Educational Technology, vol. 4, no. 1, pp. 3-18, 2008.

[18] J. Sefton-Green. (2004). Literature review in informal learning with technology outside school. [Online]. Available: 
http://www.futurelab.org.uk/resources/documents/lit_reviews/Informa 1_Learning_Review.pdf

[19] L. Hsu, "English as a foreign language learners' perception of mobile assisted language learning: A cross-national study," Computer Assisted Language Learning, vol. 26, no. 3, pp. 197-213, 2013.

[20] Z. Dörnyei, Research Methods in Applied Linguistics: Quantitative Qualitative, and Mixed Methodologies, Oxford: Oxford University Press, pp. 95-123, 2007.

[21] K. M. Thomas, B. W. O'Bannon, and V. G. Britt, "Standing in the schoolhouse door: Teacher perceptions of mobile phones in the classroom," Journal of Research on Technology in Education, vol. 46 no. 4, 2014, pp. 373-395.

[22] S. H. McDonough, Strategy and Skill in Learning a Foreign Language, London: Edward Arnold, 1995.

[23] K. Krippendorff, Content Analysis: An Introduction to Its Methodology, Thousand Oaks, Calif: Sage, 2004.

[24] F. Moretti et al., "A standardized approach to qualitative content analysis of focus group discussions from different countries," Patient Education and Counseling, vol. 82, no. 3, pp. 420-428, 2011.

[25] H.-F. Hsieh and S. E. Shannon, "Three approaches to qualitative content analysis," Qualitative Health Research, vol. 15, no. 9, pp 1277-1288, 2005.

[26] M. Schreier, Qualitative Content Analysis in Practice, Thousand Oaks, CA: Sage, 2012

[27] Ertmer and Leftwich, 2010.
Copyright (C) 2020 by the authors. This is an open access article distributed under the Creative Commons Attribution License which permits unrestricted use, distribution, and reproduction in any medium, provided the original work is properly cited (CC BY 4.0)

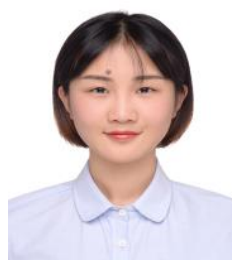

Yelinjing Liu is an undergraduate student at the College of Literature and Journalism, Sichuan University, China. While majored in teaching Chinese to Speakers of Other Languages, she has extended her learning to other domains for graduate study. Her main research interests include teaching methods and educational technologies.

She had accessed of an outstanding student of the Literature and Journalism College, SCU (2017-2018) and acquired the second-class comprehensive scholarship (2017-2018). Also, she is the vice president of a community, which called Chinese International Education Promotion Association in SCU, holding language exchange activities to help overseas students to adapt to the local life and organizing more than ten university-level Chinese language education promotion activities to expand the influence of campus activities. She has a keen interest in education and began to study this topic in early 2019 